DOI: 10.12957/demetra.2016.22492

\title{
"Fat" bodies and low-income: experiences and perceptions of mothers from Santos, Brazil
}

\section{Corpos "gordos" e baixa renda: experiências e percepções de mães na cidade de Santos, estado de São Paulo, Brasil}

\author{
Priscila de Morais Sato ${ }^{1}$ \\ Gabriela Milhassi Vedovato² \\ Kate Perepezk0 ${ }^{3}$ \\ Ramiro Fernandez Unsain \\ Mariana Dimitrov Ulian ${ }^{4}$ \\ Fernanda Baeza Scagliusi ${ }^{4}$ \\ ${ }^{1}$ Universidade Federal de São Paulo, Instituto \\ de Saúde e Sociedade, Departamento de Saúde, \\ Clínicas e Instituições. Santos-SP, Brasil. \\ ${ }^{2}$ Universidade Federal de São Paulo, Instituto de \\ Saúde e Sociedade. Santos-SP, Brasil. \\ ${ }^{3}$ Johns Hopkins University School of Medicine, \\ Department of Neuropsychiatric. Baltimore, \\ United States. \\ ${ }^{4}$ Universidade de São Paulo, Faculdade de \\ Saúde Pública, Departamento de Nutrição. São \\ Paulo-SP, Brasil. \\ Funding: The study was funded by $\mathrm{CNPq}$ \\ (numbers 487194/2013-6, 309121/2012-4 \\ and 311357/2015-6) and by a Ph.D scholarship \\ provided by the program REUNI to Priscila de \\ Morais Sato \\ Correspondência / Correspondence \\ Priscila de Morais Sato \\ E-mail: pri.sato@gmail.com
}

\begin{abstract}
The present study aimed to investigate body image among over-weight, low-income women, using their stories and life experiences to explore, describe and understand how they interpreted their body image and their weight gain process. We performed exploratory qualitative research using in-depth interviews with21 low-income women living in three different urban areas. Through content analysis we identified five aspects of the participants' body image: identity, body experiences, causes of weight gain, ways to lose weight, and body changes. The participants described their bodies in several different ways, such as fat, chubby and strong instead of clinical classifications. Most participants presented a "fat identity", which was mainly based in concrete, functional aspects of the body, rather than an aesthetic image. Difficulties in losing weight through nutritional guidance and feeling discriminated by health professionals were important barriers to engaging with the nutritionist. Our findings underscore the necessity for culturally appropriate weight-loss interventions in low-income female populations.
\end{abstract}

Key words: Body Image. Obesity. Low-Income. Mothers. Women.

\section{Resumo}

O presente estudo objetivou investigar a imagem corporal de mulheres de baixa renda a cima do peso usando suas histórias e experiências de vida para descrever e entender suas interpretações a respeito da imagem corporal e processo de ganho de peso. Para tanto, realizamos um estudo qualitativo 
exploratório, com entrevistas em profundidade com 21 mulheres de baixa renda vivendo em três áreas urbanas distintas. Por meio da análise de conteúdo, foram identificados cinco aspectos da imagem corporal das participantes: identidade, experiências corporais, causas do ganho de peso, formas de perder peso e mudanças corporais. As participantes utilizaram diversas palavras para descrever seus corpos, tais como gorda, forte e fofinha, no entanto, nenhuma classificação clínica foi usada. A maioria das participantes apresentava uma "identidade gorda", baseada em aspectos concretos e funcionais do corpo ao invés de em uma imagem estética. Dificuldade em perder peso e discriminação por parte dos profissionais de saúde foram apresentados como importantes barreiras para o engajamento com o nutricionista. Por fim, apresentamos a necessidade de intervenções para perda de peso que sejam culturalmente apropriadas a populações femininas de baixa renda.

Palavras-chave: Imagem Corporal. Obesidade. Baixa Renda. Mãe. Mulheres.

\section{Introduction}

Several studies have investigated people's relationship with their bodies, focusing mainly on body image. ${ }^{1-4}$ Body image has an early and continuous influence on one's emotions, thoughts, and behaviors. ${ }^{5}$ Paquette and Raine ${ }^{6}$ argued that body image is not a static but rather a complex and contextualized construct. Therefore, the body experience is an important construct of body image that helps to understand how humans function.

Body image is a multidimensional construct. ${ }^{5}$ Schilder ${ }^{7}$ introduces a tri-dimensional concept of body image, composed of physiological, libidinous and sociological dimensions. The physiological dimension comprehends the experience of the material aspect of the body (e.g. learning about the body through physical pain); the libidinous dimension concerns the experience of the body as a loved object and felt reality, and the sociological dimension represents the cultural influences on the felt reality of the body.

However, few studies have integrated the three dimensions of body image to investigate this construct. ${ }^{5}$ Fisher $^{8}$ warns about the disconnection between body attitudes and feelings in body image studies. Cash and Pruzinsky ${ }^{5}$ argue that understanding the depth of body experiences would be important to health scientists and clinicians, as it could provide them with insights into the role of body image in a person's quality of life. 
The contextualized investigation of body image could be relevant to understanding a heterogeneous phenomenon such as obesity, which has been observed to be more prevalent among low-income women in Brazilian and international studies. ${ }^{9-10}$ Warin et al. ${ }^{11}$ argue that, despite the attention directed towards obesity, current health promotion practices and policies have failed to address the rising rates of overweight women with a low-income economic status. According to the authors, further research that analyzes concepts of embodiment, and in particular, gendered and class-based experiences of embodiment, is needed in order to provide a better understanding of why such health inequalities persist.

Gender is as an important analytic category in the study of body image, as social expectations for bodies are very different between genders. Lupton ${ }^{12}$ advocates that any discussion on female bodies and food in the family context must incorporate in its analysis the meanings around motherhood and femininity. The study of the "embodiment of class", one's social and historical experiences and exposures, would provide important tools to understand how sociodemographic constructs, such as race, gender, social class, and weight history affect someone's vulnerability to obesity.

Studies associated African-American and Hispanic women to larger body-size ideals. While ethnicity has been well documented to play an important role in the definition of beauty models, there is still a lack of literature exploring the ways in which social class interacts with body image. . $^{13,14}$ Bourdieu ${ }^{15}$ argued that "tastes in food also depend on the idea each class has of the body and of the effects of food on the body, that is, on its strength, health and beauty (p. 190)". Nonetheless, studies in Brazil are yet to explore how groups that are vulnerable to obesity see, feel, and expect the body to look and perform.

Based on these gaps in the literature, we formulate our research question: what are body experiences and perceptions like among overweight low-income women? By using women's stories and life experiences, we aimed to explore, describe and understand the ways in which low-income women living in urban areas interpreted their body image, as well as their awareness of the process of gaining weight and the associated factors.

\section{Materials and methods}

\section{Study design}

This research is part of an ethnographic study entitled "Obesity as a heterogeneous factor: eating practices of women in social vulnerability", which was funded by $\mathrm{CNPq}$ (protocol numbers 487194/2013-6, 309121/2012-4 and 311357/2015-6) and whose primary goal was to investigate eating practices of socially vulnerable, obese mothers. 


\section{Setting}

The city of Santos is located on the coast in the Southeast region of Brazil. The city is characterized by significant social inequality; while it has the ninth highest per capita income in Brazil, $10 \%$ of its residents live in poverty. ${ }^{16}$ São Paulo State Index of Social Vulnerability points to $13 \%$ of the population in Santos living in highly or very highly vulnerable areas. ${ }^{17}$ Furthermore, around 34,000 people in Santos live in precarious conditions. ${ }^{18}$ It has been argued that the variable 'low income' in itself does not access the complexity of factors associated with living in poverty, such as environmental effects. ${ }^{19}$ Thus, for this study, we recruited mothers living in three different areas in the city classified as highly or very highly vulnerable and precarious: mount (slums), center (tenements), and northwest (stilt houses) areas.

\section{Sampling}

A purposive sample was conducted in public institutions with existing projects from the Federal University of São Paulo. The institutions were a social service assistance center (center), a children's after-school program (northwest), and a free clinic (mount). One staff member from each institution, who was familiar with the community, introduced the researcher to potential participants. This step helped the participants to create a trusting relationship with the researchers and to assure the latter's safety, as researchers were entering neighborhoods with high violence levels.

Inclusion criteria were defined as follows: a) being a mother, b) being an adult, c) living with at least one child, d) being overweight or obese, and e) living in one of the study regions. Women were considered to be overweight or obese if they had a body mass index (BMI) between 25 and $29.9 \mathrm{~kg} / \mathrm{m}^{2}$ or $\geq 30 \mathrm{~kg} / \mathrm{m}^{2}$, respectively. ${ }^{20}$ BMI was used to assure that that the target population of the study - overweight women - was reached. However, we highlight that the aim of the study was not to qualify these biomedical measurements but rather explore how participants understood and experienced their bodies.

The recruitment phase resulted in a sample of 15 participants (five per region). In order to evaluate saturation and, therefore the adequacy of sample size, one researcher performed an inductive coding of emerging themes. However, new themes were still being found by the end of the coding, indicating that saturation was not reached.

A second sampling phase took place in the same institutions, with help from staff. Researchers invited new potential participants and interviews were conducted. Two new participants from each region were included in the sample and additional coding was performed. No new relevant information contributing to the themes of the study emerged and the researchers concluded that saturation criteria were met. ${ }^{21}$ The final sample consisted of 21 mothers (seven per region). 
This study was approved by the Ethics Committee of the Federal University of São Paulo and all interviews were performed after the participants provided informed consent.

\section{Data collection}

In-depth interviews were conducted from November 2013 to December 2014 (58 interviews in all) by a dietitian and an anthropologist in the participants' homes. The interview guide was pre-tested and the list of topics included body weight during childhood, weight changes in the life course, body satisfaction, dieting and other weight loss methods, and opinions about discrimination because of body image.

The interviews were audio-recorded and fully transcribed on the same week. This strategy allowed the researchers to take notes of points to clarify, probe, and investigate in more detail during the subsequent visit. Participants were visited until no new and relevant information about the themes of interest was mentioned, thus meaning that the saturation point had been reached. The average number of visits per participant was four, ranging from three to seven visits. Notes taken by the interviewers in a field diary were later incorporated into the transcription. The average visit length was 1.5 hours, ranging from 45 minutes to 2.5 hours.

\section{Data analysis}

An exploratory content analysis was conducted using an inductive approach, which allowed for themes and codes to emerge from the data. Two researchers read the documents separately several times, making memos to highlight the most salient aspects. Further, they each separately identified quotes and expressions that seemed important and grouped them into themes, with the help of the software Atlas.ti 7.

The lists of themes were discussed until consensus was reached. Based on the themes identified, the researchers developed a codebook. Following Bernard and Ryan's ${ }^{22}$ recommendation, the codebook was composed of short and detailed descriptions of the themes; inclusion and exclusion criteria; typical and atypical exemplars, and an exemplar categorized as "close but no". Finally, the two coders independently applied the codebook to the data set, using phrases as the unit of analysis. Kappa coefficients for inter-rater reliability (Table 1) were calculated with the aid of GraphPad QuickCalcs, indicating satisfactory agreement between coders. 
Table 1. Codes and kappa coefficients from in-depth interviews with 21 low-income overweight mothers living in Santos, Brazil.

\begin{tabular}{lc}
\hline Code & Kappa \\
\hline Body during childhood & 1.000 \\
\hline Body changes & 0.902 \\
\hline Reasons for weight gain & 0.884 \\
\hline Experiences with nutritionist & 0.958 \\
\hline "I don't eat, but I am still gaining weight" & 1.000 \\
\hline Names used to describe the body & 0.727 \\
\hline Body satisfaction & 0.853 \\
\hline Body dissatisfaction & 0.891 \\
\hline Body limitations because of the weight & 0.950 \\
\hline Reasons to lose weight & 0.864 \\
\hline Stigma & 0.953 \\
\hline Physical activity & 0.968 \\
\hline Dieting & 0.945 \\
\hline Other methods to lose weight (i.e. medication and bariatric surgery) & 0.943 \\
\hline
\end{tabular}

Themes were analyzed considering their core and peripheral aspects, with attention to their central tendency, range, distribution, details, and co-occurrence. Results are presented with a detailed description, direct quotes, paraphrases, and some quantitative information, as recommended by Bernard and Ryan ${ }^{22}$.

\section{Results}

In our sample of 21 women, 15 were obese and 6 were overweight. Age ranged from 25 to 59 ; three women were 20 to 29 years old, three were 30 to 39, eleven were 40 to 49 , and four were 50 to 59. The emerging codes (Table 1) highlighted five aspects of the participants' body image: identity, body experiences, causes of weight gain, ways to lose weight, and body changes. There were no differences among themes between obese and overweight participants. Connections between aspects of body image and emerging codes are shown in Figure 1. 


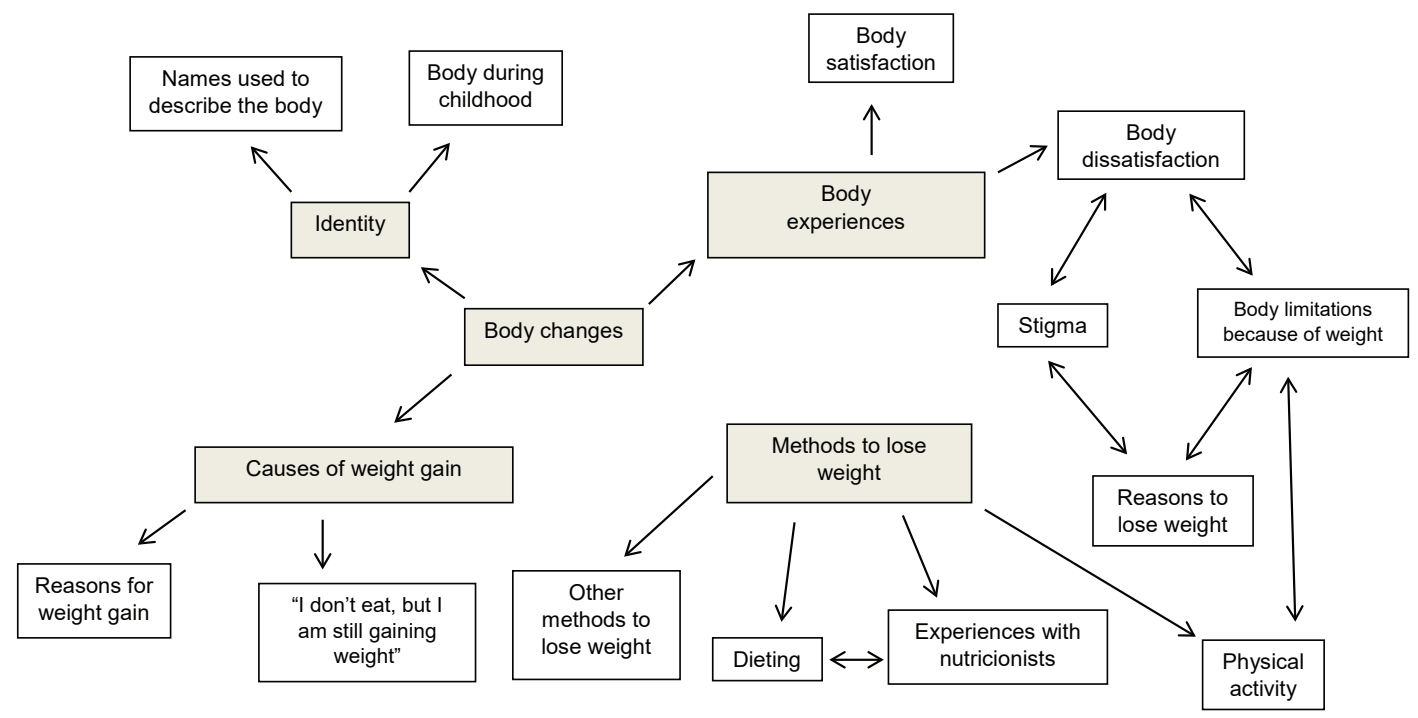

Figure 1. Themes and codes, and the interactions between them from in depth interviews with 21 low-income over-weight mothers.

Caption: the grey boxes represent themes and the white ones represent inductive codes. Single-headed arrows show the codes emerging from each theme and double-headed arrows show interactions between two codes.

\section{Identity}

The participants used several terms to describe their bodies during the interviews. However, they did not perceive themselves according to BMI classifications; only one participant used the word "obese" when reporting what the doctor had told her. "The doctors tell me I am too fat. They said I am obese, but I don't care". The most frequently used word to describe the participants' bodies was "swollen", followed by "fat", "big-boned" and "chubby".

The idea of a swollen body was very prevalent and was often used by the participants to justify their shape. In this case, the body was not "fat"; it was "swollen", usually because of medicines or diseases. "I didn’t gain weight, I got swollen. I am swollen, I am always swollen”. This was strongly emphasized by some women as a way of justifying their large body shape while differentiating themselves from "fat people".

Most women reported being thin when they were younger, while six participants have always been "fat". The acceptance of a large body through the life course helped them build an identity. One participant emphasized the importance of having a large body to deal with life constraints "I feel that because of my life's difficulties, I would be dead already if I were thin". 


\section{Body experiences}

The ways in which the participants experienced their bodies were affected by whether they incorporated their body shape into their identity. Some mothers who have always been "fat" described a process of acceptance. "I believe that when someone has a tendency to be fat, bigboned, or chubby, she has to accept her body. You don't have to worry about pleasing anyone besides yourself".

Most women were happy with their bodies; however, body satisfaction was often a dubious feeling, as many participants reported liking their bodies but wanted to lose a few pounds. "Today I think I am beautiful the way I am. Although sometimes I put on some clothes and think that if I were 8 pounds lighter they would fit me better. So, next year I'll try to lose these 8 pounds". Even though most participants would like to lose a few pounds, most of them emphasized that they did not want to lose too much weight or to become thin. "If I start to diet I lose weight fast, but I don't want to, I am feeling good about the way I am”.

The interaction between body shape and identity was also observed in reports about body dissatisfaction after a significant body change. "I gained a lot of weight in the pregnancy of the twins. I felt very bad about it". Reasons for body dissatisfaction ranged from aesthetics to health. Quotes on body aesthetics were predominant and always mentioned clothes not fitting the participants or they "not being able" to wear certain types of clothes, e.g., "I liked when I was thin because everything fit me". The participants' low-income influenced their concerns about gaining weight. Some women reported disliking gaining weight because they "lost all their clothes". "I lost almost all my clothes, lost almost everything. I had to buy new clothes in larger sizes".

Quotes on health-related body dissatisfaction were prevalent for participants with weight-related health problems and were often accompanied by reports about "suffering because of body fat". "I am suffering... I can't tell you I am happy... with all this fat". Participants referred to not being able to perform movements, and pain in their legs and back were the reasons for suffering because of body fat. Such constraints prevented participants from performing daily activities, ranging from household tasks ("I did everything sitting down. I swept the house sitting down because I couldn't stand up for long") to work duties ("I found a job as a cleaner in an office building but I couldn't keep up with the work demands").

The participants whose reason to lose weight was health were also the ones who reported having other people encouraging them to do so. The main supporters were doctors, followed by family and friends. "My husband tells me to stick to the diet. I ask him if I am fat but he says I'm not, it is because of my health". However, a few participants felt discriminated against by the doctors because of their body size, as it was assumed that they ate too much and were fat for that 
reason. "[I've been fat] since I was a kid. The doctor doesn't believe it; he thinks I am fat because I eat too much. But it is not true".

Discrimination because of body size was also reported in work environments and it ranged from others believing the participant was not capable of doing the work ("a lot of people looked at me and said: that fat woman won't be able to do it."), rejecting the participant because of her appearance ("It is hard to see a black woman working in a bank. This is discrimination. You don't find fat people working there either. This is also discrimination, and there is a lot of it."). Despite recognizing the discrimination in both situations, most participants have only experienced the first one, possibly because of the jobs for which they were eligible. "I don't think I felt stigmatized because I never... looked for a job in a bank, in a reception...”.

Almost all participants believed that people suffer discrimination because of their body sizes (fat or skinny) and around half of the participants had experienced discrimination for being fat. "People look at you and think you must be lazy". Participants described being bullied and insulted. "Nowadays I don't care as much, but I am still bullied. In my church they made a nickname for me because I am fat. I was very sad about it". While most participants said that they did not care about other people's opinions and felt good about themselves, two participants reported assimilating external discrimination. "I have prejudice against my own body because everybody would always say that I was fat, so I can't take it out of my head".

\section{Causes of weight gain}

Through the stories of their bodies, the participants listed a variety of reasons why they have gained weight (Figure 2). The most common reason for the participants was medications. The most reported medications, in order of frequency, were contraceptives, psychiatric drugs, high blood pressure drugs, and intravenous serum: "I think I gained weight after I had her (referring to her daughter), when I started to take contraceptive shots. I think they are the reason I gained weight". Eating habits and food consumption were the second most frequently reported cause for weight gain. The eating habit most commonly described was "snacking" many times a day ("I keep snacking all the time, all the time") and the most cited type of food was "junk food" ("I used to work in a street market, so I ate a lot of junk food, I think that was the reason [for weight gain])". 


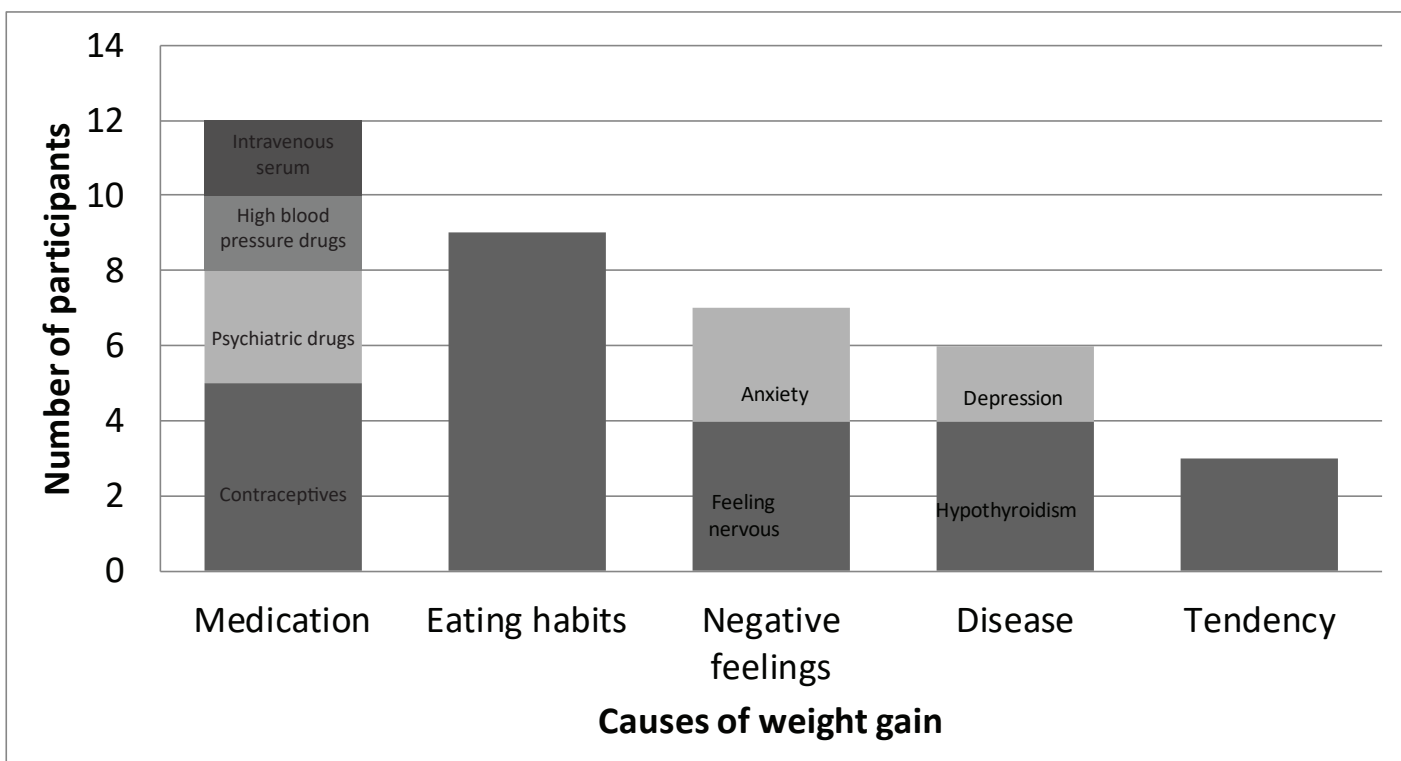

Figure 2. Native categories for causes of weight gain according to 21 low-income overweight mothers living in Santos, Brazil.

Snacking "all the time" was sometimes associated by the participants with having negative feelings, such as feeling nervous or anxious. "If I got sad, I'd go binge eating. I'd just eat". Health disorders were also reported as reasons for "being fat". In these cases, participants reported that at first they did not understand why their bodies were changing ("I didn't realize I was gaining more, more and more weight. When I went to the doctor I found out it was because I have hypothyroidism.”).

Pregnancy was reported by some women as the moment they began to gain weight and defined by them as the moment they "became fat". "I gained a lot of weight in my pregnancy [...] I gained more and more weight and couldn't lose it afterwards". Finally, a few women believed they had a "tendency to gain weight", but that was not disconnected from other factors. "I have a tendency to gain weight, of course I do, I come from a fat family... but also because the way I eat... it is all wrong".

Participants described doctors' positions regarding weight gain because of medicine drugs. Doctors' attitudes ranged from understanding to ignoring this condition to asking for a weight loss the participants felt was impossible to achieve. "I asked the psychiatrist to tell the physician that the fat that I have is not fat, it is because of the medicine I take". In these cases, the participants felt that they could do nothing to lose weight. "People say that to lose weight you just have to close your mouth, but it isn't true because my mouth is closed and I'm not losing any weight". 


\section{Methods to lose weight}

Dieting was the most often reported weight loss method. Seven participants were dieting at the moment of the interview, five of them were not dieting but had dieted before and eight had never dieted. Almost all participants dieting were doing it because of medical recommendations. "I have to lose weight because it affects my heartbeat and then I feel sick".

The types of diets reported concerned changes in the food consumed that ranged from quantity to quality. Most participants who were dieting were eating the same foods they were used to, but in smaller portions ("[the nutritionist] told me to eat just one piece of bread, sometimes I eat one but sometimes I eat two."). This group avoided fat-rich foods high and chose to eat vegetables and salads, but did not report having to buy new food products or to cook different foods for themselves because of the diet. Few participants adopted diets composed of whole grains and low-fat products.

Reasons for giving up on the diet ranged from having difficulties in avoiding some foods, such as bread, pasta, sweets, and soda, to not seeing improvement in weight loss ("I have tried to diet, but it doesn't work."). It was also possible to identify beliefs of practices associated with losing weight; the most common was leaving cubes of raw eggplant in a glass of water overnight and drinking it on the next day. Other participants mentioned drinking a glass of water when they wake up and before going to sleep. "She [friend] taught me that it helps to lose weight if you drink a glass of water in the morning before you eat anything and another one before going to bed".

The codes diet and nutritionist often overlapped, as many participants have had nutritional orientation. Opinions about nutritional treatment ranged from "helpful" and "accessible" to "impossible to follow" because the diet was too expensive. "I said, do you [the nutritionist] think I look like a millionaire? Whole grain bread, low-fat yogurt...Where do you think I will find the money to buy all this?". These different perceptions were related to the type of guidance the participants had received. Adaptations to the participant's usual food consumption were seen as easier to follow and adhere to, while diets full of whole grains and other low-energy foods were criticized for being unaffordable and thus unrealistic to them.

The lack of individualized instruction that accounted for the reality of the participant's lifestyle was an important barrier to trusting and bonding with the nutritionist. "I don't appreciate those [nutritionists] that don't care about us". Another barrier was feeling discriminated against for their body size. "Who would have the patience to be my nutritionist? I am fat, so they will look at me and think that I eat like a lion".

Other weight loss methods were weight loss drugs and bariatric surgery. Weight loss drugs have been used by a few participants; while some of them lost a lot of weight with them ("I lost a lot of weight with dieting pills, I think I lost over 40 pounds"), others thought it did not work ("You don't feel hungry but when you stop taking the pills you eat twice the amount that you would eat, 
so I decided to stop taking it.”). No participants have had bariatric surgery, but the option was discussed by three participants. While two of them desired to have the surgery ("I almost can't walk. If I had the surgery I'd lose weight and could start hiking."), the other one believed it was a bad option ("My sister almost died because of the surgery. I told her, you mutilated yourself and you didn't even lose weight.”).

\section{Body changes}

Body changes were a universal and overlapping theme in the interviews, co-occurring with codes about identity, lived experiences, and causes of weight gain. The co-occurrence of body changes and methods to lose weight were rare, indicating that the experience the participants had with such methods rarely resulted in actual body changes.

The resistance to radical body changes highlighted the role of the body in the participants' identity, as they declared they did not want to change their bodies too much because they would "feel ashamed of my body" or because they believed they could not achieve body changes because they had a "tendency to gain weight".

Most body changes experienced by the participants were weight gain, which made them dissatisfied with their bodies. Body dissatisfaction was particularly strong shortly after weight gain. Finally, the two main themes for causes for weight gain co-occurring with body changes were medications and pregnancy. Most women reported significant weight gain during pregnancy; while some were able to return to their previous weight, most of the participants could not return to their original body shape. The interaction between these themes seems important to access how participants understood the histories of their bodies and how they felt about them.

\section{Discussion}

This study is the first to explore the multi dimensions of body image in a group of overweight low-income mothers in Brazil. The language used by the participants to describe their bodies was similar to the one in the findings reported by Warin et al. ${ }^{11}$ in their study in Australia with obese women. In their study, no participants identified themselves as obese, but as "overweight", "chubby", "big boned" and "fat". The authors argue that such terms allow for the participants to distance themselves from the stigma attached to obesity.

However, in our study, contrary to the observations made by Warin et al. ${ }^{11}$, no participants classified themselves as "overweight". This seemed to indicate not only a distance from the stigma of obesity, but a distance from biomedical classifications in general, which could be related to the low-income status of the group. Coveney' ${ }^{23}$ study on lay knowledge of food among middle and 
working classes may exemplify the interaction between social class and health knowledge. The author described that while middle class participants expressed a more scientific understanding of food, food classifications by the working class were based on feelings about their effects. Our results point to a similar classification of the bodies, which was mainly based on the participant's perception of the functions and limitations of the body.

The focus on the body image instead of the classifications of overweight or obese might elucidate why there were no differences in the body image of obese and overweight participants. Instead, the category "fat", appeared to represent a broad classification of overweight bodies, and possibly a shared "fat identity". Jaffe ${ }^{24}$ states that fatness is a subjective identity built from experiences. The author presents a continuum of "fat identity" that ranges from learning that one is fat (learned identity) to feeling physical, psychological and social difficulties because of fatness (trying identity), and finally to being constantly aware of one's fatness because of its effect in all life aspects (allencompassing identity).

In our study, three participants did not recognize themselves as fat and therefore did not present "fat identities". Some participants presented just a "learned identity", with no reported consequences of being fat in their lives; however, most participants described having difficulties in their lives because of their weight. Interestingly, this did not mean that the participants were completely dissatisfied with their body. In many cases, participants did not dislike their body shape, but were unhappy about the health conditions imposed by their weight. The few women with an all-encompassing identity were the ones with higher weights, whose fatness was severely affecting their health.

The idea that the participants classified their bodies according to their lived experiences help us understand why the different "fat identities" seemed to provide better classifications to investigate the participants' body image than BMI. Within the "fat" classification, we observed a "fatter" group for whom weight was having an important impact on work and health. Thus, rather than BMI cut-offs, objective experiences of the "fat body", such as movement constraints, seemed to have a greater influence on the participants' body image perception and to be the main factor differentiating how women lived with their "fat bodies".

This orientation based on concrete experiences also permeated aspects of body dissatisfaction among participants. Contrary to some studies exploring body image in women, ${ }^{25,26}$ the participants in this study did not refer to beauty ideals portrayed by the media. Instead, needing to buy new clothes because the old ones did not fit them anymore appeared to be a more relevant reason for being dissatisfied with weight gain for some women in this low-income group. It is important to highlight that we do not mean to argue that our participants were not affected by the beauty patterns constructed by our society, but, instead, that the ways in which low-income women are affected by such models might differ from women in other social classes and should be further explored. 
Only some participants experienced the stigma associated with being fat. Our findings suggest that social class could also have a role in such beauty ideals. Most participants did not feel that being fat was a constraint to "finding a boyfriend", unlike what was observed among middle- to upper-middle class women..$^{24}$ The judgments made of the body in the participant's social circle differed from the rigid patterns in the health and work environments, where some participants reported being discriminated against. Interestingly, one participant not only accepted her large body shape, but also valued it. For her, in the context of high social vulnerability she has lived in, only the "strong fat body" could survive. The different body expectations exposed - in health, professional, social, and vulnerable environments - suggest an interaction between body ideals and contexts, showing different arrangements that will compete to affect one's body image.

Participants who "have always been fat" seemed to have strong discourses of self-acceptance and appreciation as a response to the fat stigma. This observation adds to Carr and $\mathrm{Jaffe}^{26}$ findings on higher body dissatisfaction among people who had recently experienced substantial weight changes. Although the participants reported important changes in body weight after pregnancy, this was not associated by most of them with body dissatisfaction. Counihan ${ }^{27}$ affirms that pregnancy allows women to dissociate themselves from the social stigma of being "ample". Furthermore, the status of mother and its expectations could create a "mother's body" in which taking care of others is prioritized over investing in one's vanity and image. ${ }^{28}$ The lack of investment in the body could affect this group's health. Jaffe ${ }^{24}$ describes a mother who was clinically obese participating in her research, but for whom taking care of the family was the top priority and taking care of her body was at the bottom of a hierarchy of concerns.

The gendered and class analysis of the body image provides a new entry point to understand the causes of obesity and reasons weight loss interventions fail to succeed. Several participants found it difficult to follow some of the nutritionists' suggestions because they could not afford it; however, when the nutritional recommendations were based on the participants' previously established eating habits and their financial situation, changes in their eating habits were more likely to last. Furthermore, a few participants reported feeling discriminated against by health professionals because of their bodies. Other studies have documented negative attitudes of health professionals towards overweight people. ${ }^{6}$ Thus, this study reinforces the need for future research to provide a more culturally sensitive approach to obesity interventions.

The results of this study should be considered in light of some limitations. Although the heterogeneity of BMI classifications in our sample may be seen as a limitation, we believe that it was important to allow the investigation of "fat bodies", as both overweight and obese women are considered fat by the current social norms. Further investigation into the similarities and differences of the "fat identities" of overweight and obese women could aid in understanding how people experience being fat in different ways. Finally, we understand that the body image 
construct is too complex to be profoundly investigated in one study. However, our intent was to explore the different dimensions of it, allowing the important aspects of each dimension to arise from the data, rather than deciding what to include. We believe that this inductive approach is important to bring to the surface the most relevant aspects of body image for the study population.

\section{Conclusion}

This study highlights the complex web of factors involved in the participant's perceptions of "being fat". Their low socioeconomic status was reflected in weight loss barriers and seemed to be related to a more permissive posture towards larger bodies. "Being fat" was part of most participants' identities, but not all of them. Distinctions between levels of fatness were related to body functionality rather than clinical - abstract - classifications. The centrality of concrete, functional aspects in the participants' relationship with their bodies was also expressed in their body dissatisfaction, as they seemed more concerned about the burden of buying new clothes than achieving body models presented by the media. To understand one's expectations about the body is an important consideration for health professionals to properly approach weight management. Furthermore, they should be sensitive to the constraints faced by their target population in order to provide them with tools to deal with barriers they might face. Finally, our findings underscore the necessity for culturally appropriate weight management interventions in low-income female populations.

\section{References}

1. Lewis-Smith H, Diedrichs PC, Rumsey N, Harcourt D. A systematic review of interventions on body image and disordered eating outcomes among women in midlife. Int J Coma Disord. 2016; 49(1):5-18.

2. Margolis S, Orsillo S. Acceptance and body dissatisfaction: examining the efficacy of a brief acceptance based intervention for body dissatisfaction in college women. Behav Psychother Cogn. 2016; 44(4):482-92.

3. Bailey KA, Cline LE, Gammage KL. Exploring the complexities of body image experiences in middle age and older adult women within an exercise context: The simultaneous existence of negative and positive body images. Body Image 2016; 17:88-99.

4. Tiggemann M. Considerations of positive body image across various social identities and special populations. Body Image 2015; 14:168-76.

5. Cash TF, Pruzinsky T. Body image: a handbook of theory, research, and clinical practice. New York: The Guilford Press; 2002.

6. Paquette M-C, Raine K. Sociocultural context of women's body image. Soc Sci Med. 2004; 59(5):1047-58. 
7. Schilder P. The image and appearance of the human body. New York: International Universities Press; 1978.

8. Fisher S. The evolution of psychological concepts about the body. In: Cash T, Pruzinsky T, editors. Body images: development, deviance, and change. New York: Guilford Press; 1990.

9. Ferreira VA, Magalhães R. Obesidade entre os pobres no Brasil: a vulnerabilidade feminina. Ciênc Saude Colet. 2011;16(4):2279-2287.

10. McLaren L. Socioeconomic status and obesity. Epidemiol Rev. 2007; 29(1):29-48.

11. Warin M, Turner K, Moore V, Davies M. Bodies, mothers and identities: rethinking obesity and the BMI. Sociol Health Illn. 2008; 30(1):97-111.

12. Lupton D. The heart of the meal: food preferences and habits among rural Australian couples. Sociol Health Illn. 2000; 22(1):94-109.

13. Chithambo T, Huey SJ. Black/white differences in perceived weight and attractiveness among overweight women. Journal of Obesity 2013. Disponível em: https://www.researchgate.net/ publication/236085257_BlackWhite_Differences_in_Perceived_Weight_and_Attractiveness_ among_Overweight_Women

14. Romo LF, Mireles-Rios R, Hurtado A. Cultural, media, and peer influences on body beauty perceptions of mexican american adolescent girls. Journal of Adolescent Research 2015:0743558415594424.

15. Bourdieu P. Distinction: a social critique of the judgment of taste. London: Routledge; 1986.

16. Instituto Brasileiro de Geografia e Estatística. Diretoria de Pesquisas. Coordenação de Índices de Preços. POF 2008-2009: desnutrição cai e peso das crianças brasileiras ultrapassa padrão internacional. Rio de Janeiro: IBGE; 2012.

17. Fundação Sistema Estadual de Análise de Dados. Índice Paulista de Vulnerabilidade Social. IPVS versão 2010. São Paulo: SEADE; 2004.

18. Marques E, Gomes S. Assentamentos precários no Brasil urbano. Brasília: Centro de Estudos da Metrópole; 2008.

19. Anderson AS. Nutrition interventions in women in low-income groups in the UK. Proc Nutr Soc. 2007; 66(01):25-32.

20. World Health Organization. Obesity and overweight [Internet]. jun. 2016. Disponível em: http:// www.who.int/mediacentre/factsheets/fs311/en/

21. Patton MQ. Qualitative evaluation and research methods: New York: Sage Publications; 1990.

22. Bernard H, Ryan G. Analyzing qualitative data: systematic approaches: New York: Sage Publications; 2010 .

23. Coveney J. A qualitative study exploring socio-economic differences in parental lay knowledge of food and health: implications for public health nutrition. Public Health Nutr. 2005; 8(03):290-7. 
24. Jaffe K. Forming fat identities [doctoral]. [New Brunswick, NJ]: Department of Sociology, Rutgers University; 2008.

25. Webb JB, Warren-Findlow J, Chou Y-Y, Adams L. Do you see what I see?: An exploration of interethnic ideal body size comparisons among college women. Body Image 2013; 10(3):369-79.

26. Carr D, Jaffe K. The psychological consequences of weight change trajectories: evidence from quantitative and qualitative data. Econ Hum Biol. 2012; 10(4):419-30.

27. Counihan C. The anthropology of food and body: gender, meaning, and power. Hove, UK: Psychology Press; 1999.

28. Sato PM, Pereira PR, Stelmo IC, Fernandez Unsain R, Ulian MD, Sabatini F, et al. Eating practices and habitus in mothers. A Brazilian population-based survey. Appetite 2014; 82:16-28. 
